\title{
Retraction
}

\section{Retracted: The Mechanical Performance of Shear Key of Immersed Tube Tunnel with Differential Foundation Settlement}

\author{
Journal of Sensors \\ Received 10 January 2017; Accepted 10 January 2017; Published 3 April 2017 \\ Copyright (C) 2017 Journal of Sensors. This is an open access article distributed under the Creative Commons Attribution License, \\ which permits unrestricted use, distribution, and reproduction in any medium, provided the original work is properly cited.
}

At the request of the authors, the article titled "The Mechanical Performance of Shear Key of Immersed Tube Tunnel with Differential Foundation Settlement" [1] has been retracted. The authors found that there was an error in the method used for the data processing as temperature change was not considered, and the results were inconsistent with those in the thesis of Bin ShengLin [2], who was acknowledged in the article. Thus, the accuracy of the reported data and the conclusions of this article are not reliable.

\section{References}

[1] X. Weng, Y. Feng, and Y. Lou, "The mechanical performance of shear key of immersed tube tunnel with differential foundation settlement," Journal of Sensors, vol. 2016, Article ID 2841753, 9 pages, 2016.

[2] B. ShengLin, The experimental study and theoretical analysis on mechanical behavior of immersed tube tunnel section joint [M.S. thesis], Chang'an University, 2013. 


\title{
The Mechanical Performance of Shear Key of Immersed Tube Tunnel with Differential Foundation Settlement
}

\author{
Xiaolin Weng, Ying Feng, and Yuanpeng Lou
}

Key Laboratory for Special Area Highway Engineering of Ministry of Education, Chang'an University, Xian 710064, China

Correspondence should be addressed to Xiaolin Weng; 49768532@qq.com

Received 18 April 2015; Revised 12 August 2015; Accepted 4 October 2015

Academic Editor: Francesco Baldini

Copyright (C) 2016 Xiaolin Weng et al. This is an open access article distributed under the Creative Commons Attribution License, which permits unrestricted use, distribution, and reproduction in any medium, provided the original work is properly cited.

A fiber Bragg grating (FBG) based sensor network was developed to monitor the strain distributions within immersed tube tunnel shear key, which was subjected to differential settlements. An improved packaging and installation method of the quasi-distributed sensor system was utilized, which not only ensured a high sensor survival rate but also achieved accurate measurement of axial strains. Based on the monitoring results, the stress variations of shear keys of the immersed tunnel joint, which originate from the buckling caused by the longitudinal differential siltation at seabed and the surface defects, were analyzed in detail.

\section{Introduction}

It has been common practice for engineers to obtain information on the state of geostructures (such as pile foundations, bridges, dams, and tunnels) by monitoring those structures. Electric resistance (ER) and vibrating wire (VW) gauges have been commonly used for field instrumentation of civil structures; however, lead wires from conventional strain gauge systems sometimes make the installation difficult and adversely affect structural integrity. Moreover, the quality of the output of such sensors depends on such factors as the existence of electromagnetic fields and the skills of those involved in setting up the instrumentation [1]. Recently, fibre optic sensors have been successfully integrated with many civil engineering fields ranging from concrete structures [2-7] to soil problem. These technologies have shown unique advantages over conventional monitoring methods, including tiny size, high sensitivity, immunity to EMI, good durability, and the ability of multiplexing. The early-stage study on the feasibility of fiber optic sensing in tunnel monitoring was introduced by Mohamad et al. [8], Wang et al. [9], and Li et al. [10]. It is shown that there is certain discrepancy between field measurement data of strain distribution and theoretical results. A majority of previous research on embedded FBG sensors was conducted on small scale specimens. Little attention has been paid to the embedding of multiplexed FBG sensors for application in large concrete structures where conditions are harsh.

Along with the increase of cross-sea and cross-river tunnels, the construction of immersed tube tunnel method gets attention gradually. Joints are weak but are significant links in immersed tube tunnels. Misplace and opening of the immersed tunnel joint due to the uneven tube section settlement can bring great threat to the safety of shear key on immersed tunnel joint. So carrying out the research of the experimental study and theoretical analysis on mechanical behavior of immersed tube tunnel section joint has very important practical value. The stress and deformation mechanisms of joint shear keys for immersed tunnels are extremely complicated due to the complex marine environment, engineering geology, and hydrogeological conditions of the immersed tunnel along with deep-sea loading conditions. Therefore, it is important to develop a new settlement-testing platform with which to conduct a largescale physical modeling experiment and to investigate the stress and deformation mechanisms along with the strainstiffening point of shear keys of immersed tunnel joints under typical working conditions. It is additionally significant to assess the long-term stability and durability of the entire immersed tunnel. The main purpose of this paper is to investigate stress variations of shear keys of the immersed tunnel joint, which originate from the buckling caused by 


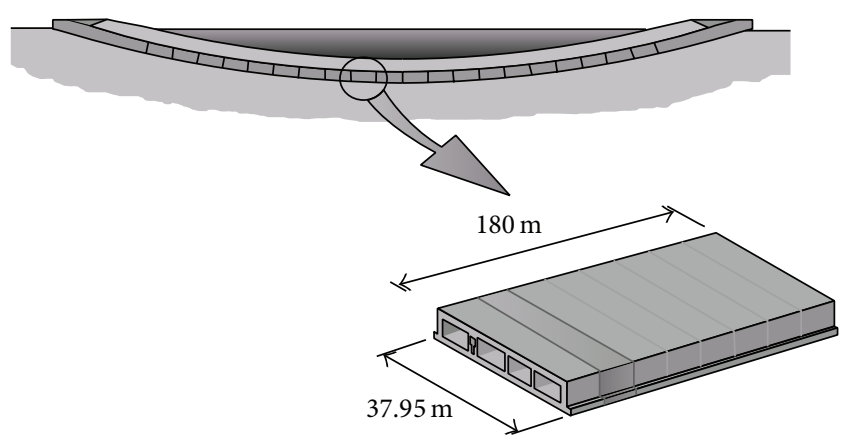

FiguRE 1: Immersed tunnel tube section.

the longitudinal differential siltation at seabed and the surface defects.

\section{Research Background}

The undersea tunnel of the Hong Kong-Zhuhai-Macao Bridge is around 5,990 meters long, and it uses rectangular, reinforced concrete sectional tubes. The main body of the tunnel is comprised of thirty-two tubes, with the length of each tube of $180 \mathrm{~m}$ and the maximum burial depth approximately of $43.6 \mathrm{~m}$. The length of each segment is $22.5 \mathrm{~m}$, the width $37.95 \mathrm{~m}$, the height $11.4 \mathrm{~m}$, and the lining thickness $1.5 \mathrm{~m}$ (Figure 1). The flank and the top and bottom boards, all composed of C50 reinforced concrete, are $1.5 \mathrm{~m}$. The siltation thickness from the tunnel roof to the original sea bed reaches $23 \mathrm{~m}$, with the longitudinal length approximately $3 \mathrm{~km}$. The tunnel project has distinctive features, which include but are not limited to the long tube segment, deep burial, high loading of siltation, strikingly different strata, difficulty in settlement control, high earthquake-resistance standards, and complicated construction at the island tunnel junction. Figure 2 shows the longitudinal arrangement of the seabed immersed tunnel of the Hong Kong-Zhuhai-Macao Bridge. Immersed tunnels built on soft soil foundations have shown settlement to varying degrees. In existing immersed tunnels, the movement and opening of the tube shear keys, which result from uneven settlement among the tubes, threaten the safe operation of immersed tunnels.

\section{Fiber Bragg Grating Sensor Technology}

In the field of fiber optic sensors (FOSs), the FBG sensors are one of the most exciting developments in recent years. They have a unique property and many advantages over other FOSs due to their quasi-point sensing and multiplexing capability. The most important advantage of an FBG sensor is that the measured data is encoded directly in terms of the wavelength, which is an absolute parameter and does not suffer from disturbances of the light paths. Hence, the output signal is independent of the intensity of the source and losses in the connecting fibers and couplers. Furthermore, each of the reflected signals will have a unique wavelength and can be easily monitored; an array of wavelength-multiplexed FBG sensors may thus be implemented for simultaneous multiple measurements using a single fiber. As shown in Figure 3, the sensing functioning of FBG was firstly discovered on the formation of photogenerated gratings in germanosilicate optical fibre by Hill et al. [11]. The Bragg grating is written into a segment of $\mathrm{Ge}$-doped single-mode fibre in which a periodic modulation of the core refractive index is formed by exposure to a spatial pattern of ultraviolet (UV) light. According to Bragg's law, when a broadband source of light has been injected into the fibre, FBG reflects a narrow spectral part of light at a certain wavelength [12]

$$
\lambda_{B}=2 n_{\mathrm{eff}} \Lambda
$$

where $\lambda_{B}$ is the Bragg wavelength, typically 1510 to $1590 \mathrm{~nm}$ $\left(1 \mathrm{~nm}=10^{-9} \mathrm{~m}\right), n_{\text {eff }}$ is the effective core index of refraction, and $\Lambda$ is the period of the index modulation.

Through physical or thermal elongation of the sensor segment and through the change in the refractive index of the fibre due to photoelastic and thermooptic effect, the Bragg wavelength will change linearly with strain and temperature. Considering a standard single-mode silica fibre, $\lambda_{B}$ changes linearly with the applied strain $\Delta \varepsilon$ and temperature $\Delta T$. This relationship is given by [13]

$$
\frac{\Delta \lambda_{B}}{\lambda_{B 0}}=c_{\varepsilon} \varepsilon+c_{T} \Delta T,
$$

where $\lambda_{B 0}$ is the original Bragg wavelength under strain free and initial temperature condition, $\Delta \lambda_{B}$ is the variation in Bragg wavelength due to the applied strain and temperature, and $c_{\varepsilon}$ and $c_{T}$ are the calibration coefficients of strain and temperature. The typical strain and temperature accuracy of a bare $\mathrm{FBG}$ sensor are $1 \mu \varepsilon$ and $0.1^{\circ} \mathrm{C}$, respectively.

\section{Experimental Procedures}

4.1. Foundation Settlement Simulation System. Simulating the marine environment in the terrestrial environment for the sake of experimentation will entail difficulties, such as loading application, fabrication and handling of models, and the simulation of typical working conditions. To solve such problems, existing testing platforms for foundation settlement should be further developed and transformed. For instance, the upgraded platform should be an integrated multifunctional testing platform for foundation settlement, and it should include loading, preloading, model casting, model handling, and the accurate simulation of working conditions, among other features, so that it can be used to conduct large-scale modeling experiments and can provide strong support for large-scale loading experiments.

The model test was conducted in the Laboratory of Large Scale Simulation of Foundation Settlement at Chang'an University. The tester is mainly composed of the jacking system, supporting system, and the monitoring system. The jacking system can simulate the amount and rate of settlement; apart from a number of industrial computers and sensors, it employs more than 100 self-lock jacks which are uniformly spaced in rows (Figure 4). The test platform forms the supporting system by itself, and the monitoring system is made up of monitoring elements and Data Acquisition 

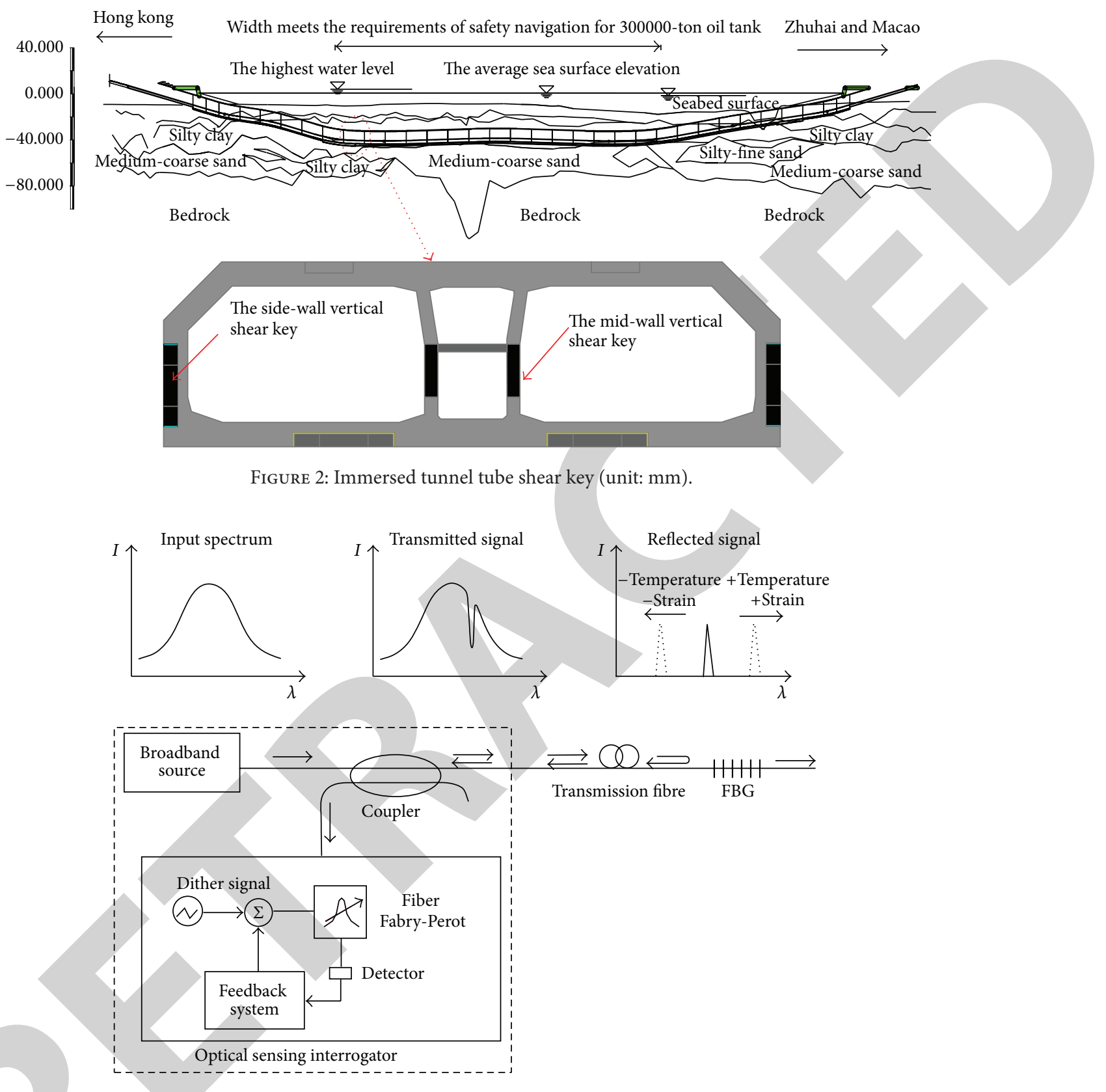

FIGURE 3: Strain and temperature sensing of an FBG sensor.

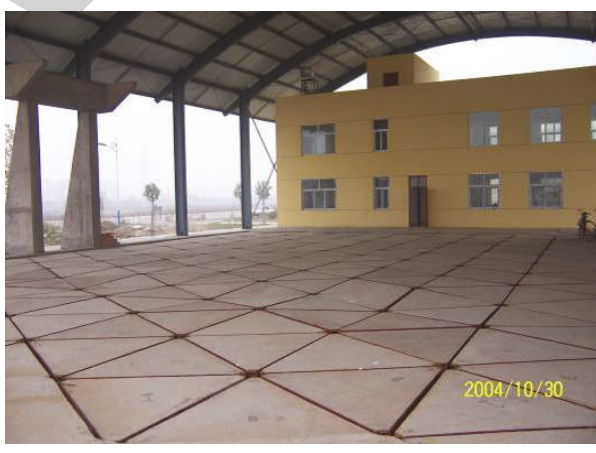

(a) Close-up view of the test rig panels

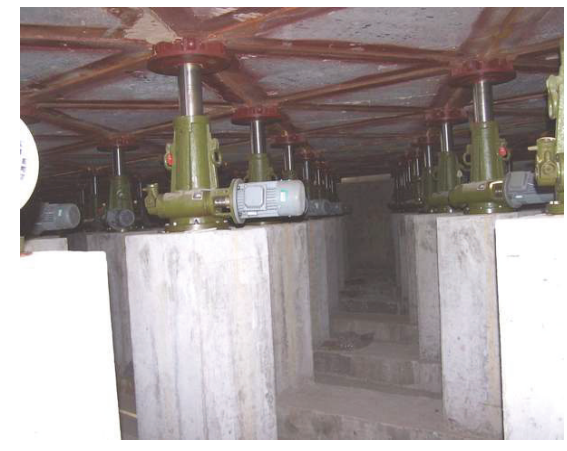

(b) Close-up view of the hydraulic jacks

FIGURE 4: Jacking system for simulation of foundation settlement. 


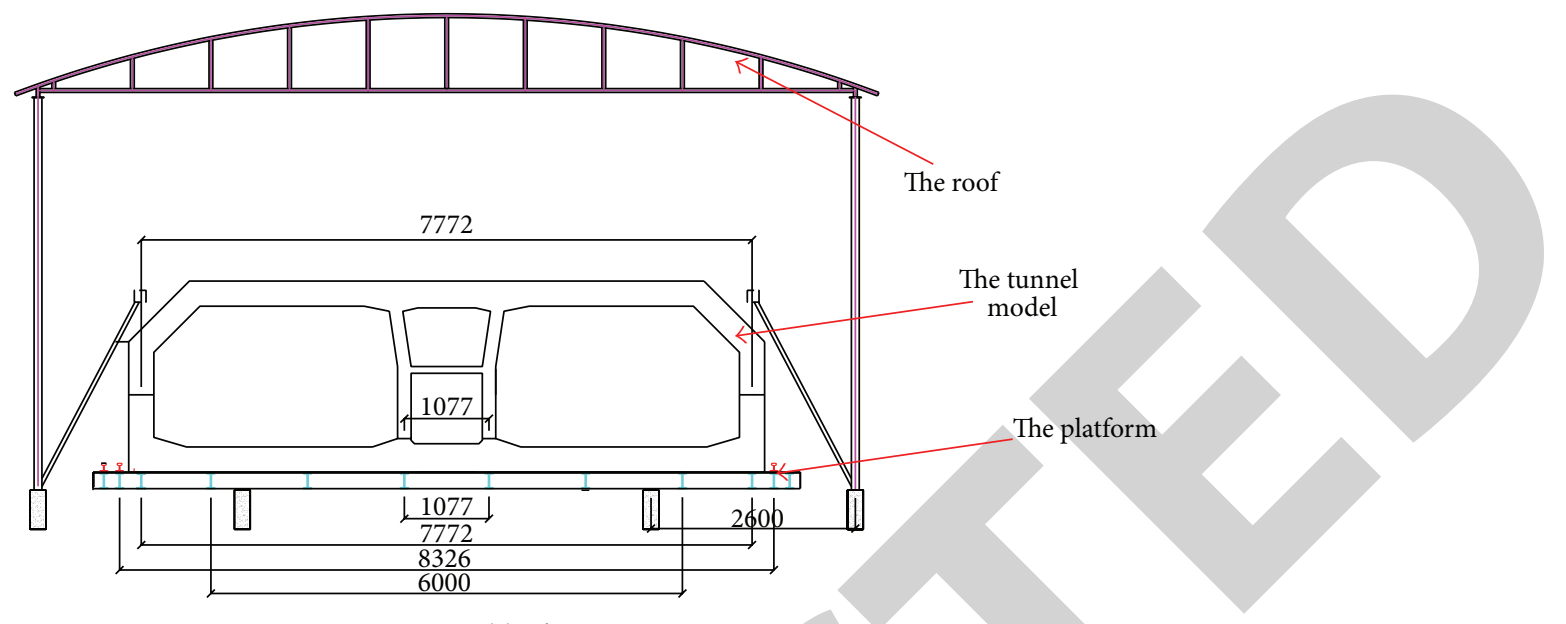

(a) Elevation view

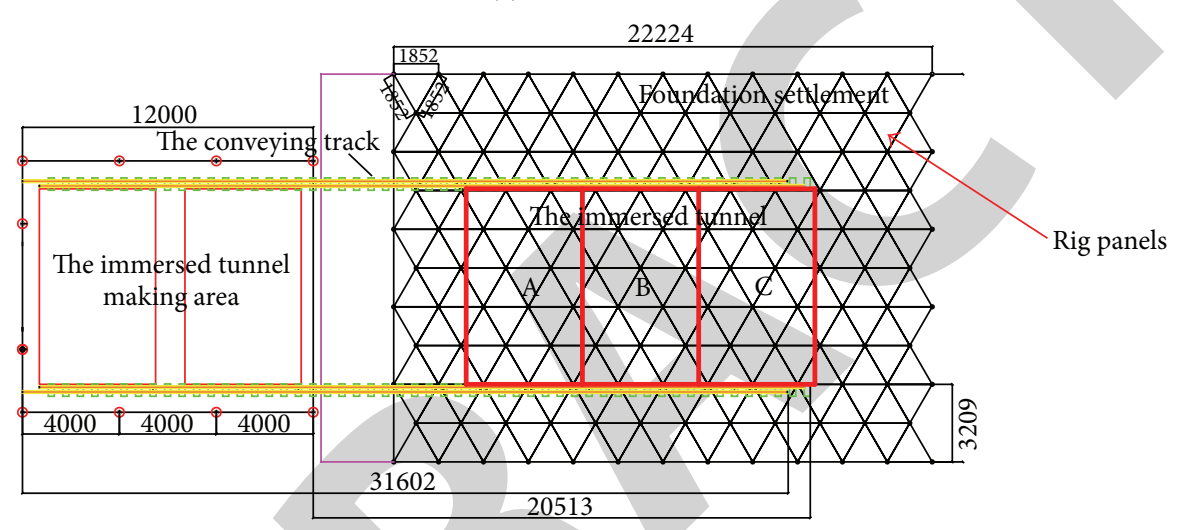

(b) Vertical view

FIGURE 5: Layout of immersed tube modeling (unit: mm).

System (DAS). The platform is used to simulate the ground surface; it consists of a number of panels, which achieve certain dynamic effect when assembled together. The points at the corner or the joint of panels are regarded as the settlement nodes on curve. The lift of jacks in different position could be adjusted to achieve required settlement in different location of the foundation.

Based on the large-scale settlement testing platform, a terrestrial testing system was transformed to simulate the marine engineering environment to test an immersed tube segment. However, in a real scenario, the tube section will be subjected to reaction forces coming from the sea bed and also to forces from the sediment above. But subject to experimental conditions, in this model experiment, a typical and easy buckling working condition was selected for practical engineering purposes. In light of the buckling caused by longitudinal uneven siltation and strata defects, the test could be conducted such that the central control system controls the testing platform. Differential settlement could be realized by controlling the settlement sequence and the settlement basin of the working conditions being simulated. Figure 5 shows the layout of the immersed tube tunnel on the settlement platform.
Following investigation and comparison, the model similarity scale was determined to be $1: 4.69$. As for the size of actual immersed tunnel, each tube width is $37.95 \mathrm{~m}$, tube length $22.5 \mathrm{~m}$, and the height $11.4 \mathrm{~m}$. According to the engineering geological conditions of the tunnel, corresponding equipment was added and transformed to meet the requirements of the experiment, ensuring that it would be suitable for the surroundings and site while exerting little impact on the performance of the existing experiment platform. The accuracy of the test should be met, and the strength, stiffness, and stability of the existing experimentplatform facilities should be considered. The eastern side adopted a bracing scheme in response to the limited space. The existing retaining wall and northern abutment were used in the experiment, and the gravity retaining wall of the masonry structure was constructed at the west side on the test bed for settlement. A $40 \mathrm{~cm}$ deep sand layer was laid between the model and the lower plate, which could alleviate the impact of friction between the model and the lower plate on the eccentric compression of mechanical helix lifting jacks. It would also reduce the impact of stress concentration caused by nonuniform contact between the model and the triangle plate. 
TABLE 1: Longitudinal bending condition.

\begin{tabular}{|c|c|c|c|c|}
\hline Test working & \multicolumn{3}{|c|}{ The bending style } & The maximum \\
\hline $\mathrm{T}-1$ & A & B & $\mathrm{C}$ & $12 \mathrm{~cm}$ \\
\hline $\mathrm{T}-2$ & A & B & $\mathrm{C}$ & $12 \mathrm{~cm}$ \\
\hline $\mathrm{T}-3$ & A & B & $\mathrm{C}$ & $12 \mathrm{~cm}$ \\
\hline $\mathrm{T}-4$ & A & B & $\mathrm{C}$ & $12 \mathrm{~cm}$ \\
\hline T-5 & A & B & $\mathrm{C}$ & $12 \mathrm{~cm}$ \\
\hline
\end{tabular}

According to the actual buckling working condition of the testing platform, the maximum differential settlement between the second immersed-tube center and the first immersed-tube edge could be controlled within $12 \mathrm{~cm}$. There are five buckling working conditions in total, with the maximum settlement of the jack being $12 \mathrm{~cm}$. Table 1 shows the buckling configurations of the $\mathrm{A}, \mathrm{B}$, and $\mathrm{C}$ tubes.

4.2. Test Scheme for Component Designs. To adapt to the model's extensive fabrication process, packaging was designed and the installation method was used for the fiber Bragg grating sensors. After the testing, the survival rate of the sensors reached $90 \%$, suggesting the feasibility of the packaging and installation method. The length of the Bragg optic grating was $10 \mathrm{~mm}$, the interval $5 \mathrm{~mm}$, the center wavelength $1510 \sim 1590 \mathrm{~nm}$, the band width $0.3 \mathrm{~nm}$, and the reflectivity larger than $80 \%$. The SM125 FBG interrogator, produced by Micron Optics in the United States was used to receive and process monitoring data. The modeling experiment was conducted primarily to investigate the mechanical and deformation performance of the shear keys at the section joint. For this reason, the measurement of the shear key, including the corner, should be the focus of the testing measurement system.

According to existing research materials, under the buckling working conditions, the vertical shear keys-or the sidewall shear keys and the mid-wall shear key-have loadsharing effects. The horizontal shear key, however, does not bear any forces. Therefore, under the buckling working conditions, testing components were deployed only on the vertical shear keys.

However, being thin, the optical fiber itself has only limited tension and shear resistance; therefore, the application of effective sensor protection measures for the experiment is very important. Before the fiber grating was encapsulated into shear keys, the bare grating was wrapped in four layers of thermal plastic pipe. This packaging technology ensures the survival rate of the fiber grating sensor. The packaged and installed fiber Bragg grating was initially pasted to a $0.5 \mathrm{~mm}$ thick, hollowed-out iron plate, which was protected by resin colloid. The rectangular steel frame was welded to the back of the steel plate. Then the steel frame and the shear key were welded together. Four fiber Bragg grating sensors systems were designed in this experiment; each system is $4 \mathrm{~m}$ long, with 6 gratings sensors carved on each fibre optical, as shown in Figure 6(b), and 3 grating strain gauges constitute a set of strain rosette to measure one point. To get contrast data, eight sets of strain rosette, or 24 strain gauges, were deployed at different positions of each shear key, are numbered $1,2, \ldots, 8$. The detailed layout of this is shown in Figure 6. As the FBG sensor is sensitive for both strain and temperature, one key problem in data analysis is to separate the effect of temperature from the strain monitoring data. During the model test, the temperature compensation problem is achieved by adding a conventional temperature sensor to shear key with the same temperature field. Once the temperature $\Delta T$ is measured, the mechanical strain can be corrected as follows:

$$
\Delta \varepsilon=\frac{1}{c_{\varepsilon}}\left(\frac{\Delta \lambda_{B}}{\lambda_{B}}-c_{T} \Delta T\right) .
$$

Then the stress-strain transformation formula is as follows:

$$
\Delta \lambda_{0}=\frac{\lambda_{0}\left(1-P_{e}\right) \Delta \sigma}{E}=K_{S} \Delta \sigma,
$$

where $E$ is elastic modulus of fiber materials, $P_{e}$ is elastooptical coefficient of optical fiber, and $K_{S}$ is sensitivity for measuring strain; Because the main material of optical fiber is quartz, $P_{e}$ is $0.22, E$ is $7.0 \times 10^{7} \mathrm{~Pa}$, and $K_{S}$ is $1.12 \times 10^{-7} \mathrm{~Pa}^{-1}$.

\section{Testing Result Analysis}

5.1. Principal Stresses of the Joint Shear Key. The layout of the immersed tubes on the settlement platform is shown in Figure 7. The experiment included the monitoring of principal strain caused by differential settlement between the side-wall and mid-wall vertical shear keys at the A-B and B-C cross sections, respectively. Based on the monitoring results, the stress variations of shear keys, which originate from the buckling caused by the longitudinal differential siltation at seabed and the surface defects, were calculated and analyzed in detail. The results are shown in Figures 8 and 9 .

An analysis of Figure 8(a) reveals that the first principal stress of the A-B cross section has similar trends and values under working conditions 1,2 , and 3 , whereas the stress values are relatively large at positions 6 and 8. This information suggests that the settlement of the $\mathrm{C}$ tube has relatively little effect on the side-wall shear key at the A-B cross section and the tension occurs mainly at the joints between the shear key and the tube. Under working conditions 4 and 5 , the stress values of monitoring positions $5,6,7$, and 8 , at the lower part of the shear key, entail little variation, whereas the stress values at these same four positions at the upper part increase correspondingly. This data suggests that the differential settlement between tubes $\mathrm{A}$ and $\mathrm{B}$ has a substantial impact on the first principal stress at the upper part of the shear key, while the stress values at the lower part do not change substantially. The least favorable stress occurs 


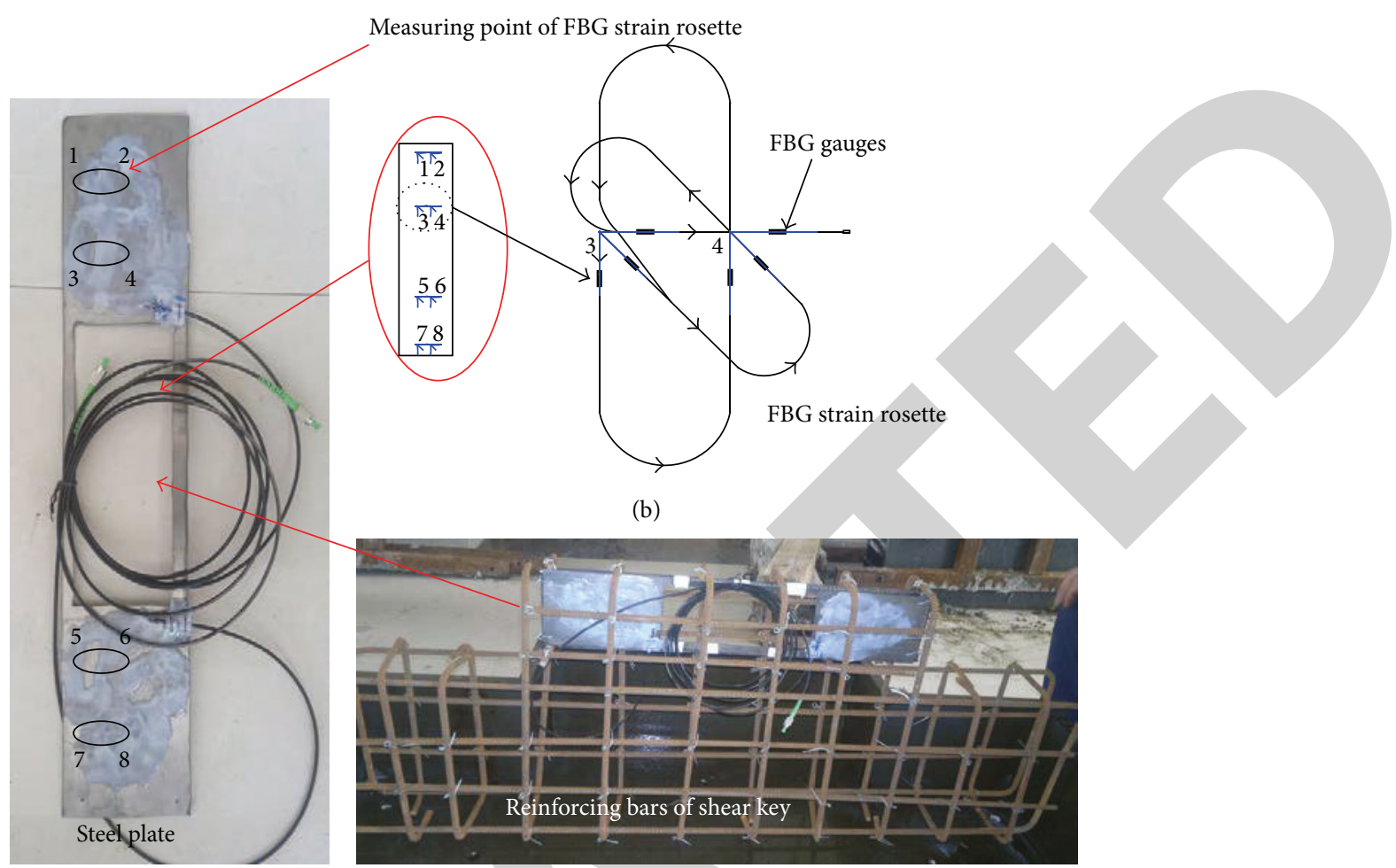

(c)

(a)

FIGURE 6: The position of FBG test element in shear key.

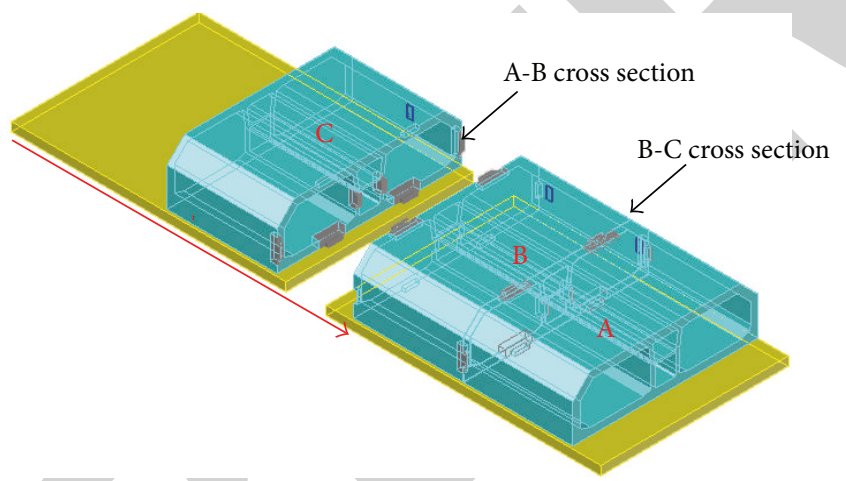

FIGURE 7: Shear keys strain testing section.

at positions 1 and 6 , with stress value of $0.74 \mathrm{MPa}$. An analysis of Figure 8(b) shows that first principal stress of the $\mathrm{B}-\mathrm{C}$ cross section has similar trends and values under working conditions 3,4 , and 5 , whereas the stress value is relatively large at position 6 . This suggests that the settlement of the A tube has relatively little effect on the first principal stress of the side-wall shear key at the B cross section and that the tension occurs mainly at the joints between the shear key and the tube. Based on a comparison of the results under the five working conditions, it has been determined that the variation of the differential settlement between the $\mathrm{B}$ and $\mathrm{C}$ tubes has a relatively large impact on the positions $5,6,7$, and 8 at the lower part of the shear key. The stress values at the upper part, however, do not change significantly. The least favorable stress occurs at position 6 under working condition 5, with stress value of $0.92 \mathrm{MPa}$. Analysis of Figure 8(c) reveals that, similarly to the side-wall shear key, the first principal stress of the A-B cross section has similar trends and values under working conditions 1,2 , and 3 . It suggests that settlement of the $\mathrm{C}$ tube has relatively little effect on the first principal stress of the mid-wall shear key at the A cross section. Compared with the first principal stress of the side-wall shear key, the stress level of the mid-wall shear key is relatively low. The least favorable loading occurs at position 4 under the working condition 1, with stress value of $0.098 \mathrm{MPa}$. By analyzing Figure $8(\mathrm{~d})$, it can be determined that the first principal stress of the $\mathrm{B}-\mathrm{C}$ cross section has similar trends and values under working conditions 3,4 , and 5 . This information suggests that settlement of the A tube has relatively little effect on the first principal stress of the mid-wall shear key at B cross section. Similar to the situation of the mid-wall at the A cross section, the first principal stress is much lower than that of the sidewall shear key. The least favorable loading occurs at position 4 under working condition 5 , with stress value of $0.12 \mathrm{MPa}$.

Based on an analysis of Figure 9(a), it can be seen that the third principal stress of the side-wall shear key has similar trends and values at the A-B cross section. This suggests that $C$ tube settlement has relatively little effect on the third principal stress of the mid-wall shear stress at the A cross section. The least favorable loading occurs at position 6 under working condition 1 , with stress value of $0.081 \mathrm{MPa}$. Analysis of Figure 9(b) reveals that the third principal stress of 


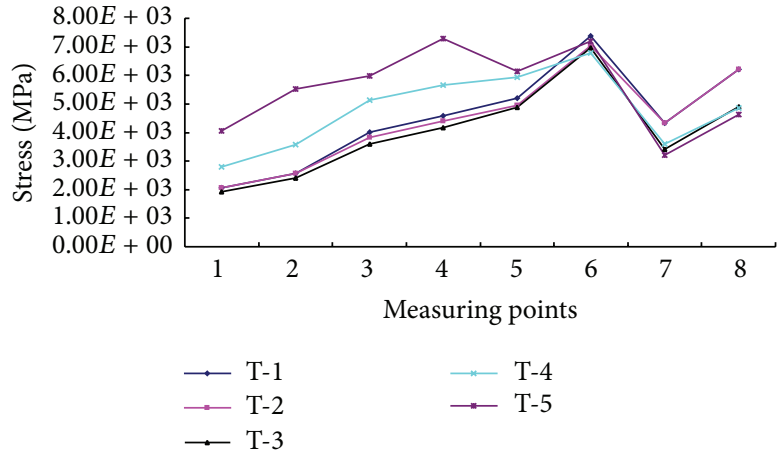

(a) Side-wall vertical shear keys of A-B cross section
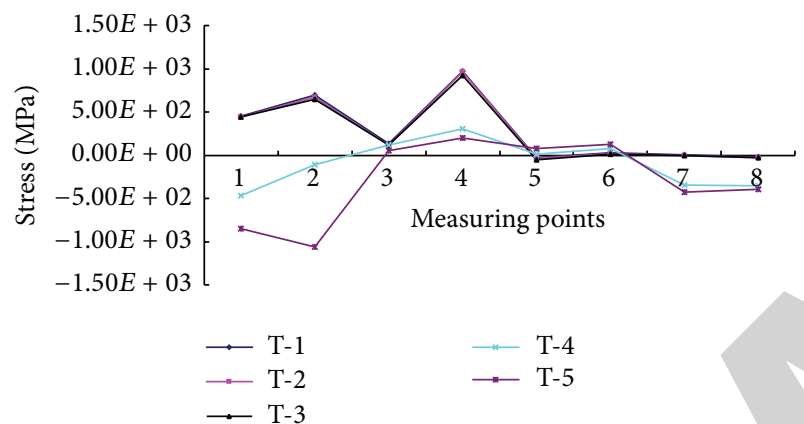

(c) Mid-wall vertical shear keys of A-B cross section

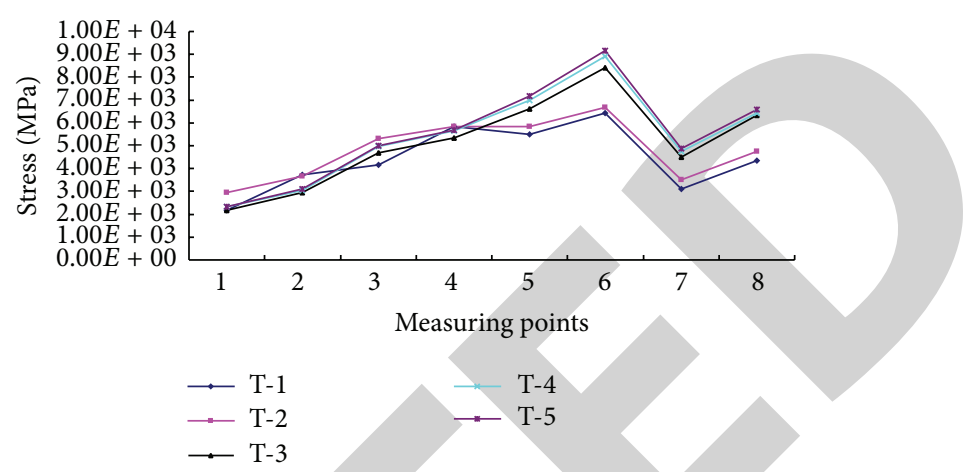

(b) Side-wall vertical shear keys of B-C cross section

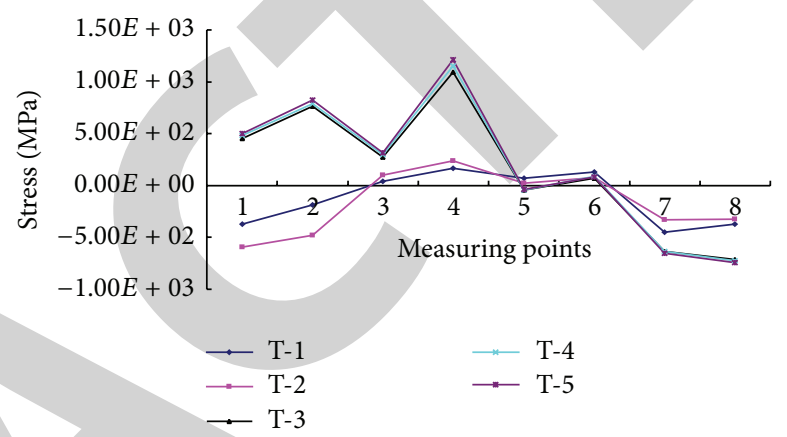

(d) Mid-wall vertical shear keys of B-C cross section

FIGURE 8: The first principal stress of shear key.

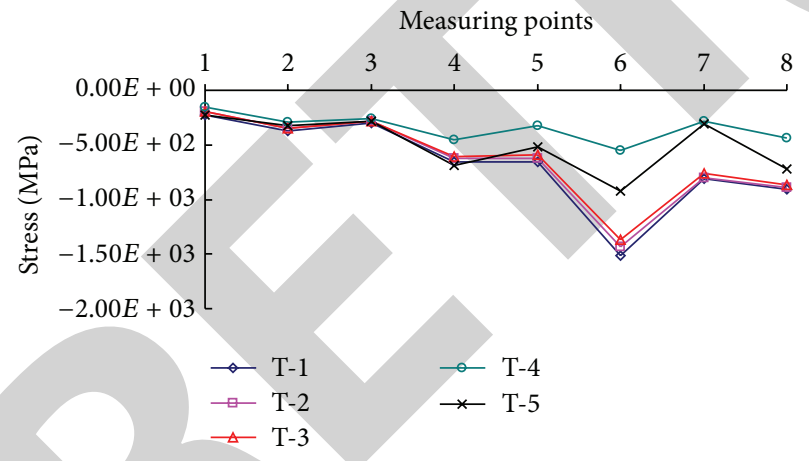

(a) Side-wall vertical shear keys of A-B cross section

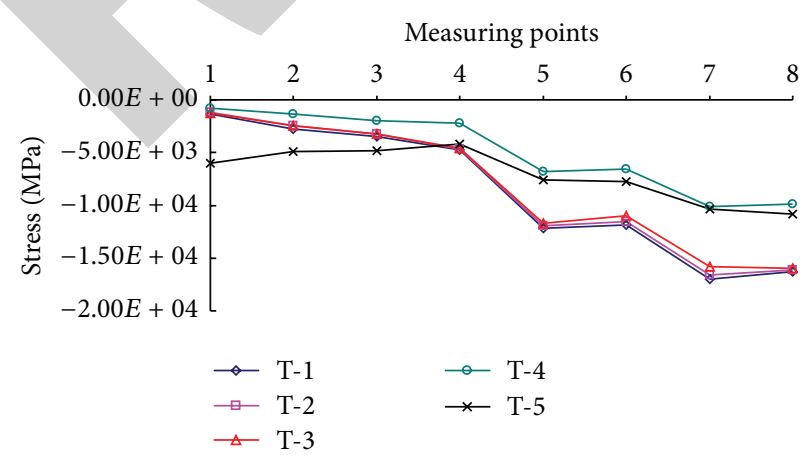

(c) Mid-wall vertical shear keys of A-B cross section

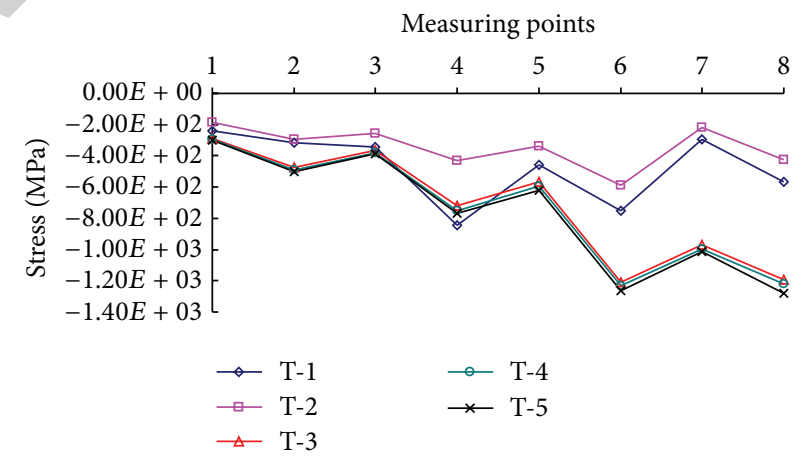

(b) Side-wall vertical shear keys of B-C cross section

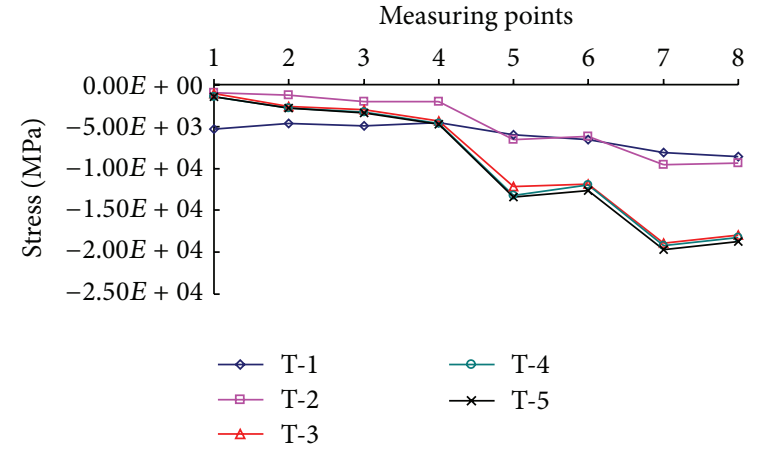

(d) Mid-wall vertical shear keys of B-C cross section

FIgURE 9: The third principal stress of shear key. 


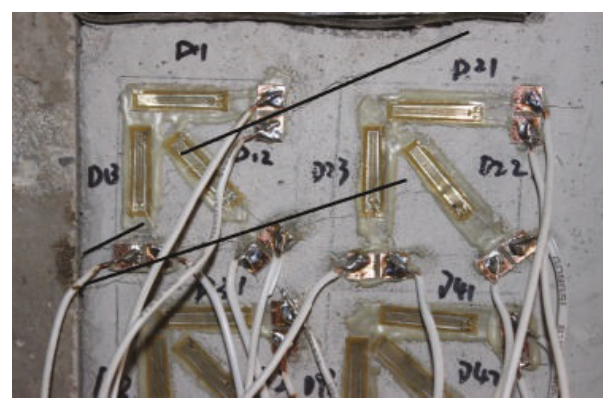

(a) The mid-wall shear key

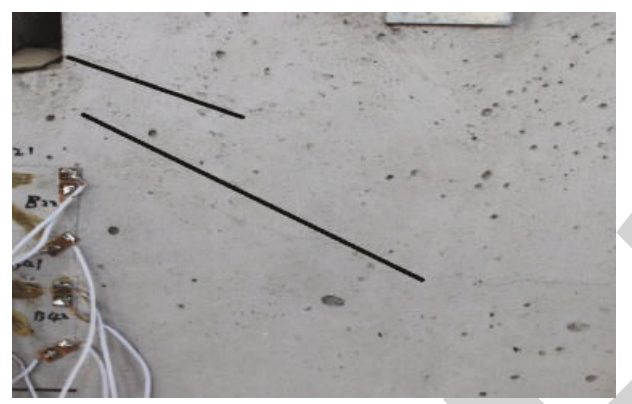

(b) The side-wall shear key

FIgURE 10: Typical crack pattern of shear keys.

the side-wall shear key has similar trends and values at the $\mathrm{B}-\mathrm{C}$ cross section. It suggests that settlement of the A tube has relatively little effect on the third principal stress of the mid-wall shear key at the B cross section. The least favorable loading occurs at position 8 under working condition 5 , with stress value of $0.13 \mathrm{MPa}$. Comprehensive monitoring results shows that the third principal stress of the side wall is at a relatively low level. By analyzing Figure 9(c), it can be seen that the third principal stress of the mid-wall shear key at the A-B cross section mainly occurs at the lower part of the shear key. The stress values increase from the top to the bottom, with positions 7 and 8 featuring relatively large stress values. The least favorable loading occurs at position 7 under working condition 1 , with stress value of $1.6 \mathrm{MPa}$. This information makes it clear that compression stress mainly occurs at the contact area between the shear key tenon and the lower corner of the shear key trough. Analysis of Figure 9(d) shows that the condition of the third principal stress of the mid-wall shear key at the B-C cross section is similar to that of the mid-wall shear key at the A cross section. The third principal stress mainly occurs at the lower part of the shear key, which increases from the top to the bottom, with positions 7 and 8 featuring relatively large stress values. The least favorable loading occurs at position 7 under working condition 5, with stress value of $1.9 \mathrm{MPa}$.

5.2. Damage Analysis of Bending Working Conditions. The differential settlement between the two ends of a single segment increases from $4 \mathrm{~mm}$ to $12 \mathrm{~mm}$. As the differential settlement increased, the mid-wall shear key began developing microcracking, which was followed by obvious cracking (Figure 10(a)). The damage occurred at the crash side, where the front end of the shear key contacts with the shear key trough; the failure angle and the horizontal plane form an angle of approximately $25^{\circ}$, which was compression dominant damage. The damage also occurred at the joint section falling between the shear key and the lining, with the failure angle and the horizontal plane forming an angle of approximately $70^{\circ}$, which pulled force dominant damage. The side-wall shear key incurred cracking at a later time (Figure 10(b)). The damage was mainly confined to the joint between the shear key and the immersed tunnel, with the failure angle and the horizontal plane forming an angle of $20^{\circ}$, which was compression dominant damage. The horizontal shear key was not damaged. The above results show that compressed crack emerged easily at the corner of the end of shear key, whereas pulling crack emerged at the joint between the shear key and the lining. In the design process, such positions warrant special attention.

\section{Conclusions}

This paper presents the applicability and reliability of an FBG sensing system to an immersed-tunnel shear keys model testing. Multiplexed FBG sensors were embedded in the shear keys and internal strains were measured. First, the strain properties of the test shear keys were identified using an FBGbased sensor. The failure test was then carried out on the test shear keys. It was found that the FBG sensing system is capable of measuring the internal strains of the shear keys. From this experimental study, the following conclusions are drawn:

(1) The side-wall shear key exerts pulling stress on the joint between the shear key and the tube, which is unfavorable to the concrete stress. Thus reinforcement processing should be considered.

(2) The mid-wall shear key is mainly pressured, and the lower part of the shear key bears relatively high load, particularly the contact area between shear key tenon and shear key trough.

(3) The differential settlement between the tubes has little effect on other neighboring segments. Stress concentrations occur at the joint and contact angle of the shear key at varying degrees, where consolidation handling should be conducted.

The success of the test encourages the use of the FBG sensing system as an alternative to a conventional system based on electric-type sensors, which also provide actual feasibility of having FBG sensors installed in the real tunnel infrastructure.

\section{Conflict of Interests}

The authors declare that there is no conflict of interests regarding the publication of this paper. 


\section{Acknowledgments}

The authors would like to acknowledge the financial support of the National Natural Science Foundation of China and the testing support provided by Dr. Ma Haohao and Dr. Bin Shenglin.

\section{References}

[1] W. Lee, W.-J. Lee, S.-B. Lee, and R. Salgado, "Measurement of pile load transfer using the Fiber Bragg Grating sensor system," Canadian Geotechnical Journal, vol. 41, no. 6, pp. 1222-1232, 2004.

[2] B. Bonfiglioli and G. Pascale, "Internal strain measurements in concrete elements by fiber optic sensors," Journal of Materials in Civil Engineering, vol. 15, no. 2, pp. 125-133, 2003.

[3] Q. Li, G. Li, and L. Yuan, "Calibration of embedded fiber optic sensor in concrete under biaxial compression," Measurement: Journal of the International Measurement Confederation, vol. 35, no. 3, pp. 303-310, 2004.

[4] Q. Li, G. Li, G. Wang, F. Ansari, and Q. Liu, "Elasto-plastic bonding of embedded optical fiber sensors in concrete," Journal of Engineering Mechanics, vol. 128, no. 4, pp. 471-478, 2002.

[5] H.-H. Zhu, J.-H. Yin, L. Zhang, W. Jin, and J.-H. Dong, "Monitoring internal displacements of a model dam using FBG sensing bars," Advances in Structural Engineering, vol. 13, no. 2, pp. 249-261, 2010.

[6] H.-H. Zhu, A. N. L. Ho, J.-H. Yin, H. W. Sun, H.-F. Pei, and C.-Y. Hong, "An optical fibre monitoring system for evaluating the performance of a soil nailed slope," Smart Structures and Systems, vol. 9, no. 5, pp. 393-410, 2012.

[7] H.-H. Zhu, B. Shi, J.-F. Yan, J. Zhang, C.-C. Zhang, and B.J. Wang, "Fiber Bragg grating-based performance monitoring of a slope model subjected to seepage," Smart Materials and Structures, vol. 23, no. 9, Article ID 095027, 2014.

[8] H. Mohamad, K. Soga, P. J. Bennett, R. J. Mair, and C. S. Lim, "Monitoring twin tunnel interaction using distributed optical fiber strain measurements," Journal of Geotechnical and Geoenvironmental Engineering, vol. 138, no. 8, pp. 957-967, 2012.

[9] F. Wang, D. M. Zhang, H. H. Zhu, H. W. Huang, and J. H. Yin, "Impact of overhead excavation on an existing shield tunnel: field monitoring and a full 3D finite element analysis," Computers, Materials \& Continua, vol. 34, no. 1, pp. 63-81, 2013.

[10] C. Li, Y. Sun, Y.-G. Zhao et al., "Monitoring pressure and thermal strain in the second lining of a tunnel with a Brillouin OTDR," Smart Materials and Structures, vol. 15, no. 5, article N107, 2006.

[11] K. O. Hill, B. Malo, F. Bilodeau, D. C. Johnson, and J. Albert, "Bragg gratings fabricated in monomode photosensitive optical fiber by UV exposure through a phase mask," Applied Physics Letters, vol. 62, no. 10, pp. 1035-1037, 1993.

[12] W. W. Morey, G. Meltz, and W. H. G. Glenn, "Fiber optic bragg grating sensors," in Fiber Optic and Laser Sensors VII, vol. 1169 of Proceedings of SPIE, pp. 98-107, Boston, Mass, USA, 1990.

[13] A. D. Kersey, M. A. Davis, H. J. Patrick et al., "Fiber grating sensors," Journal of Lightwave Technology, vol. 15, no. 8, pp. 1442-1463, 1997. 